\title{
The Role of Pirani Scoring System in the Management and Outcome of Idiopathic Club Foot by Ponseti Method
}

\author{
Dr. Alok Aggarwal ${ }^{1}$, Dr. Neha Gupta ${ }^{2}$ \\ ${ }^{1}$ Senior Resident, Department of Orthopaedics, JLN Hospital, Ajmer, India \\ ${ }^{2}$ Senior Demonstrator, Department of Pathology, JLN Hospital, Ajmer, India
}

\begin{abstract}
Background: Clubfoot is not an embryonic malformation. A normally developing foot turns into a clubfoot during the second trimester of pregnancy. Therefore, like developmental hip dysplasia and idiopathic scoliosis, clubfoot is a developmental deformation. Understanding the pathomechanics and treating successfully clubfoot has always been unsolved mystery for modern medicine. Clubfoot is usually diagnosed immediately after birth simply by looking at the foot. Most Orthopaedic surgeons have agreed that the initial treatment of a clubfoot should be nonsurgical and start as soon as possible after birth. Pirani et al has developed a reliable and valid method of clinically assessing the amount of deformity present in an unoperated congenital clubfoot less than 2 years of age. It allows the treating practitioner to know how patient is responding to treatment, to know when tenotomy is indicated, and to reassure parents regarding progress. Material and method: The subjects included in the study were consecutive patients presenting with Idiopathic CTEV attending Orthopaedic OPD from December 2014 to December 2015. Results: In total there were 25 children (38 feet) presented with idiopathic clubfoot deformity, treated by Ponseti technique. Most of the children were below 6 week of age. When mobility of feet was analysed with respect to different Pirani Score groups, It was also found that mean Pirani Score of supple and rigid feet were 4.76 and 5.5 respectively. The more severe the initial deformity higher Pirani Score, the more casts were required to obtain correction. Conclusion: The study clearly showed that age at initial presentation, quality (mobility) of foot and Pirani Score at presentation, has a direct bearing on final results.
\end{abstract}

Keywords: Congenital Talipes Equinovarus (CTEV), Pirani Score, Ponseti Method

\section{Introduction}

Club foot, also called congenital talipes equinovarus (CTEV), is a congenital deformity involving one foot or both. Clubfoot is usually diagnosed immediately after birth simply by looking at the foot. Most orthopaedic surgeons have agreed that the initial treatment of clubfoot should be nonsurgical and started as soon as possible after birth. A variety of manipulations, splinting, strapping, bracing, and casting techniques have been advocated in an attempt to achieve correction of the deformity ${ }^{1-12}$. Although some success with nonsurgical treatment has been reported in the literature, results have often been less than optimal, with partial corrections, recurrence and other complications ${ }^{2,13-16}$.

Large number of patients coming to our centre from nearby districts, the unsatisfactory results associated with complete soft tissue releases at ten to fifteen years of follow-up ${ }^{17,18}$ and good to excellent results by Ponseti technique reported by many authors ${ }^{12,17,19-23}$ encouraged us to study the subject with the aim of assessing the efficacy of Ponseti technique in correcting CTEV deformity of foot, determining the type of clubfoot best suited for this technique and to minimize the surgical and anaesthetic exposure. The lacunae, disadvantages and sequel of Ponseti technique were also looked for.

Clinical assessment has been the oldest method of assessing the deformity. Initially, Ponseti and Smoley ${ }^{2}$ described an assessment method, which was purely subjective and based on the severity of the deformity and flexibility of foot. Pirani et $\mathrm{al}^{23}$ has developed a reliable and valid method of clinically assessing the amount of deformity present in an unoperated congenital clubfoot less than 2 years of age. It allows the treating practitioner to know how the patient is responding to treatment, to know when tenotomy is indicated, and to reassure parents regarding progress.

The Pirani severity scoring system registers the deformity of six different components of the clubfoot, comprising of two Scores i.e. Midfoot Score and Hind foot Score, scoring six clinical signs, each component is given a Score of $0,0.5$ or 1.0

\section{Midfoot Score}

Three signs comprise the Midfoot Score (MS), grading the amount of midfoot deformity between 0 and 3.Curved lateral border, Medial crease, Talar head coverage

\section{Hind foot Score}

Three signs comprise the Hind foot Score (HS), grading the amount of hindfoot deformity between 0 and 3.Posterior crease, Rigid equine, Empty heel Consequently, the total Score is from 0 to 6 points, with 6 representing the most severe deformity. In the present study we have used Pirani severity scoring system for assessing clubfoot deformity.

\section{Material and Method}

The study was conducted on 38 feet of 25 consecutive patients presenting with CTEV attending Orthopaedic OPD from December 2014 to December 2015. Use of Pirani Score 


\section{International Journal of Science and Research (IJSR) \\ ISSN (Online): 2319-7064 \\ Index Copernicus Value (2013): 6.14 | Impact Factor (2015): 6.391}

Every clubfoot under Ponseti management was "Scored" at each week for HS, MS, and TS (Total Score).The scores were plotted on a graph to know how the foot was recovering on the treatment. Achilles Tenotomy was indicated when HS>1, MS $>1$ and the head of the talus was covered. After calculating Pirani Severity Score at initial presentation and at weekly interval during follow up, it was noted in proforma specially made for it.

\section{Categorization of feet}

The feet were then classified into three categories with respect to the severity of the deformity on basis of initial Pirani Score.

Group I -Feet with a Pirani Score of 1.5 to 2.5 points

Group II -Feet with a Pirani Score of 3 to 4.5 points

Group III -Feet with a Pirani Score of 5 points or more

\section{Treatment Regimen}

The Ponseti technique ${ }^{24,25}$ was used at our institution. The patients returned in 5 to 7 days and the casts were removed. The mobilization and casting were continued at each visit, with simultaneous correction of the cavus, adduction deformity and heel varus. The equinus was not addressed until all other deformities were corrected, and the foot was able to be abducted $50^{\circ}$ to $60^{\circ}$ on the talus. A simple percutaneous tenotomy of the Achilles tendon was performed if residual equinus was observed i.e. after the abduction of the foot and the varus deformity of the heel have been corrected.

After the last cast was removed and once all deformities were corrected, the patients were given foot abduction brace (FAB). Patients were evaluated every 15 days until the age of six months and then every month after initial completion of treatment to encourage parental compliance to FAB and to evaluate maintenance of correction.

\section{Observation and Statistical Analysis}

The present study was carried out in Department of Orthopaedics, JLN Medical College \& Associated Group of Hospitals, Ajmer Rajasthan. The subject included in the study were consecutive patients presenting with Idiopathic CTEV attending Orthopaedic OPD from December 2014 to December 2015.In total, there were 25 children (38 feet) presenting with idiopathic clubfoot deformity, and treated by Ponseti technique.

Most of the children were below 6 weeks of age. The youngest patient in the series was of 3 weeks, while oldest was of 26 weeks. Treatment was initiated at a mean age of 9.08 weeks (range - 3 to 26 weeks). Treatment was started at less than three months of age in 20 patients (80\%). In only 3 patients, treatment was initiated at more than 18 weeks of age. Males predominated, constituting about $72 \%$ of the sample population. The male to female ratio in the series was 2.5: 1 . Of the 25 patients, $12(48 \%)$ had unilateral and $13(52 \%)$ had bilateral involvement. In unilateral series, right side was found to be more commonly involved (52\%) when compared to left (48\%). Two patients out of 25 had positive family history for similar deformity of foot. Sibling and parent involvement was found in one case while grandparent and cousin involvement was found in the other case.

Foot was classified into supple type, if manual reduction was possible and rigid type where manual reduction was impossible. By this method $66 \%$ feet were rated as supple and $34 \%$ as rigid at the time of initial presentation. Two children $(8 \%)$ were treated with a cast before initial presentation at our institute with a mean of 7.8 casts (range, 5 to 10 casts) having been applied. No patient had any corrective surgery before presentation.

Showing Pre-Treatment Pirani Scores (According to
\begin{tabular}{|c|c|c|c|c|}
\hline S. No. & Group & Sc ore & No. of feet & Percentage \\
\hline 1 & I & $1.5-2.5$ & 0 & 0 \\
\hline 2 & II & $3.0-4.5$ & 13 & 34 \\
\hline 3 & III & 5 or more & 25 & 66 \\
\hline & Total & & 38 & 100 \\
\hline
\end{tabular}

The deformity was classified according to Pirani Scoring System into 3 groups. Group I with a score of $1.5-2.5$ points was not seen in any foot $(0 \%)$, Group II category with a score of 3 to 4.5 points was seen in 13 feet $(34 \%)$ and group III the most common category with a score of 5 points or more was seen in 25 feet $(66 \%)$.In the present study majority of the feet $(66 \%)$ were having pretreatment Pirani Score between 5 or more.

In Feet classified in Group II and Group III, mean Pirani Score was 4.13 and 5.42 respectively. Overall, mean Pirani Score for all feet was 5.01.On comparing Pirani score with age at presentation, it was found that patients presenting early after birth were having mild or moderate deformity belonging to group I and group II while patients presenting late were having more severe deformity belonging to group II and group III.

Patient presenting in the early age belonged to group I and II, and were of supple variety while those patients presenting late were in group II and III and of rigid variety. It was also found that mean Pirani Score of supple and rigid feet were 4.76 and 5.5 respectively.

In group II with score of 3-4.5 points, 1 foot (8\%) underwent percutaneous tenotomy, while in group III with score of 5 points, 13 feet $(52 \%)$ required tenotomy. Total of $14(37 \%)$ of the 38 clubfeet underwent percutaneous Achilles tenotomy to correct residual equinus deformity. It was also found that mean Pirani Score of tenotomy feet 5.35 was higher than non-tenotomy feet 4.81 .

There were 15 complications among all the casting performed, constituting $39 \%$ of total feet. Majority of complications were minor erythema $40 \%$ seen in young neonates that may be due to soft skin followed by blisters in $33 \%$. No infections, skin necrosis, neurovascular compromise or bleeding were observed even in post tenotomy period.

\section{Volume 5 Issue 6, June 2016 www.ijsr.net}




\section{International Journal of Science and Research (IJSR) \\ ISSN (Online): 2319-7064 \\ Index Copernicus Value (2013): 6.14 | Impact Factor (2015): 6.391}

\section{Results}

At end of the study, we observed that $84 \%$ patients showed good results with Pirani score $<1.5$, fair in $4 \%$, and poor results observed in $12 \%$ of the cases. Hence, $88 \%$ patients showed statisfactory results.Even patients classified under group I did not required any open tenotomy or posterior release to correct the deformity showing $100 \%$ results. About $100 \%$ of the patients having Pirani Score less than or equal to 4.5 showed good results with Ponseti technique. However $68 \%$ of the patients under group III also claimed good result, with $24 \%$ patients having poor results.

\section{Comparison of results with pirani score at presentation}

\begin{tabular}{|c|c|c|c|c|c|c|c|c|c|}
\hline S. & Foot & \multicolumn{2}{|c|}{ Good } & \multicolumn{2}{|c|}{ Fair } & \multicolumn{2}{|c|}{ Poor } & \multicolumn{2}{|c|}{ Total } \\
\cline { 3 - 10 } No. & Grade & Foot & $\%$ & Foot & $\%$ & Foot & $\%$ & Foot & $\%$ \\
\hline 1 & I & 0 & 0 & 0 & 0 & 0 & 0 & 0 & 0 \\
\hline 2 & II & 13 & 100 & 0 & 0 & 0 & 0 & 13 & 100 \\
\hline 3 & III & 17 & 68 & 2 & 8 & 6 & 24 & 25 & 100 \\
\hline & Total & 30 & 79 & 2 & 5 & 6 & 16 & 38 & 100 \\
\hline
\end{tabular}

\section{Discussion}

The mean age at initial presentation of 9.08 weeks is in agreement with age incidence observed by Dobbs et $\mathrm{al}^{21}$ who reported clubfeet in 51 patient at mean age of 12 weeks, at initial presentation. While in the study of 70 patients by Leeveg and Ponseti ${ }^{26}$, the mean age was 6.9 weeks at initial presentation. A mean age of 10.8 weeks was reported by Lehman et $\mathrm{al}^{27}$ in a series of 30 patients treated by Ponseti technique. However, Herzenberg et $\mathrm{al}^{22}$ reported a study of 27 patients in which all the patients presented within 3 month of age.

The mean age of patients having rigid clubfoot (13 weeks) as compared to supple clubfoot (6.8 weeks) was definitely higher. The mean pirani Score was much higher in patients having late presentation (Mean Pirani Score $=5.5$ ) as compared to patients who have early initial presentation (Mean Pirani Score $=4.43$ ).

The age of initial presentation also had a bearing on need of tenotomy as showed that only $27 \%$ of cases required tenotomy where age of initial presentation was below 6 weeks, whereas tenotomy was required in 100 of cases, in those presented after 18 weeks of age. However after excluding those feet who had required PMSTR (failure with Ponseti technique) a very statistically significant was obtained, when need of tenotomy, was compared with patients presenting at age less than 3 months of age to those presenting at more than 3 months of age.

The above observation clearly showed that initial age at presentation has a direct bearing on quality (mobility) of foot, Pirani Score, the need of tenotomy and final results . The indication for tenotomy has been clearly described and is reported to be necessary in approximately $44 \%$ patients. Tenotomy of the Achilles tendon is an integral part of Ponseti technique. If residual equinus was observed after complete correction of adduction and varus deformity or when $15^{0}$ of dorsiflexion could not be obtained with the use of casts, a simple percutaneous tenotomy of the Achilles tendon was performed which allowed more expeditious correction of the clubfoot deformity, decreasing the number of casts and the overall duration of treatment. In the present study, in group-II with Score of 3 to 4.5 points, 1 foot (8\%) underwent percutaneous tenotomy, while in group-III with Score of 5 or more points 13 feet $(52 \%)$ required tenotomy . This is showing strong relation between higher Pirani Score at initial presentation and need of tenotomy.

In the present study the mean number of casts that were applied to obtain correction in group I, II and III were $0,7.4$ and 8 respectively. The more severe the initial deformity, the more casts were required to obtain correction. However, overall mean number of cast for all groups was 7.7 (range, three to nine casts), which is quite similar to Laaveg and Ponseti $^{26}$ and Herzenberg et $\mathrm{al}^{22}$ series, number of casts ranges from 1 to $7,90 \%$ of the patients required 5 casts for correction. Lehman et $\mathrm{al}^{27}$ was able to obtain correction with casting averaged 5.4 (range being 4-9). Similarly Scher et $\mathrm{al}^{28}$ reported mean number of casts as (5.7) range (4-9), while Dobbs et $\mathrm{al}^{21}$ required 4.16+1.23 (range 3-7 casts) cast for correction.

In the present study, the families of 3 children (12\%) admitted that they had not complied with use of the FAB. Similar observation regarding noncompliance of the $29 \%$ cases was observed by Lehman et al. However in study of Morcuende et $\mathrm{al}^{20}$ only $10 \%$ of the cases showed noncompliance. While high preponderance of noncompliance of $41 \%$ was noted by Dobbs et $\mathrm{al}^{21}$ in his study. In the present series, $8 \%$ of the patients ( 2 children) reported relapses with Pirani score more than 5 after initial successful treatment. Similar observations were reported by Morcuende et $\mathrm{al}^{20}$, who reported that three were $17(10 \%)$ relapses. While Dobbs et $\mathrm{al}^{21}$ reported relapses in sixteen infants $(31 \%$, twenty- seven feet) at a mean age of six months (range 3-18 months), when there was 50 hind foot varus and/or $<15^{\circ}$ of ankle dorsiflexion. Ponesti has reported a relapse rate of $78 \%$ in patients noncompliant with the FAB and a relapse rate of $7 \%$ in compliant patients. All of the noncompliant patients in Ponesti's ${ }^{29}$ series were corrected with recasting. In all 6 relapse in this study, the parents admitted to noncompliance with the FAB.

\section{Conclusion}

The study showed that there is direct correlation between the increase incidence of tenotomy with higher Pirani Score, with increased rigidity of clubfoot and with higher age at presentation.

\section{References}

[1] Kite JH : The clubfoot. Philadelphia : Grune \& Stratton, 1964.

[2] Ponseti IV, Smoley EN : Congenital clubfoot : the results of treatment. J. Bone Joint Surg. 1963; 45 A : 261-275.

[3] Ikeda K : Conservative treatment of idiopathic clubfoot. J. Pediatr. Orthop. 1992; 12 : 217-223.

[4] Bensahel H, Guillaume A, Czukonyi Z, Desgrippes Y : Results of physical therapy for idiopathic clubfoot : a long term follow-up study. J. Pediatr. Orthop. 1990; 10 : 189-192.

Volume 5 Issue 6, June 2016 


\section{International Journal of Science and Research (IJSR) \\ ISSN (Online): 2319-7064}

Index Copernicus Value (2013): 6.14 | Impact Factor (2015): 6.391

[5] DeValentine SJ, Blakeslee TJ : Congenital talipes equinovarus. In Foot and ankle disorders in children. Edited by SJ DeValentine. New York : Churchill Livingstone, 1992.

[6] Blakeslee TJ : Congenital idiopathic talipes equinovarous (clubfoot). Current Concept Clin Podiatr Med Surg. 1997; 14 : 9-56.

[7] Scarpa A : A memoir on the congenital club feet of children and the mode of correcting that deformity. 1818 Clin Orthop. 1994; 308 : 4-7.

[8] Kite JH : Non operative treatment of congenital clubfoot. Clin. Orthop. 1972; 84 : 29-38.

[9] McKay DW : New concept and approach to clubfoot treatment. Section II correction of the clubfoot. J. Pediatr Orthop. 1983; 3 : 10-21.

[10] Simons GW : The clubfoot : the present and a view of the future. New York, Springer Verlag, 1994.

[11] Turco VJ : Resistant congenital clubfoot : one stage posteromedial release with internal fixation : a follow up report of a fifteen year experience. J. Bone Joint Surg. (Am) 1979; $61:$ 805-14.

[12] Nutt JJ : Diseases and deformities of the foot. EB Treat, New York, 1915.

[13] Aronson J, Puskarich CL : Deformity and disability from treated clubfoot. J. Pediatr. Orthop. 1990; 10 : 109-119.

[14] Karksi T, Wosko I : Experience in the conservative treatment of clubfoot. in newborns and infants. J. Pediatr Orthop. 1989; 9 : 134-136.

[15] Wesely MS, Barenfeld PA, Barrett $\mathrm{N}$ : Complications of the treatment of clubfoot. Clin. Orthop. 1972; 84 : 93-96.

[16]Miller JH, Bernstein SM : The roentgenographic appearance of the "corrected clubfoot". Foot Ankle. 1986; $6: 177-183$.

[17]Cooper DM, Dietz FR : Treatment of idiopathic clubfoot : a thirty year follow up note. J. Bone Joint Surg (Br) 1995; 77 : 1477-89.

[18] Ippolito E, Farsetti P, Caterini R, Tudisco C : Long term comparative results in patients with congenital clubfoot treated with two different protocols. J. Bone \& Joint Surg. 2003; 85 A (7) : 1286-1294.

[19] Colburn M, Williams M : Evaluation of the treatment of idiopathic clubfoot by using the Ponseti Method. J. Foot Ankle Surg. 2003; 42 (5) : 259-67.

[20] Morcuende JA, Dolan LA, Dietz FR, Ponseti IV : Radical reduction in the rate of extensive corrective surgery for clubfoot using the Ponseti method. J. Pediatr. Orthop. 2003; 23 (6) : 780-7.

[21] Dobbs MB, Rudzki JR, Purcell DB, Walton T, Porter KR, Gurnett CA : Factors predictive of outcome after use of the Ponseti method for the treatment of idiopathic clubfeet. J. Bone Joint Surg Am 2004; 86 A (1) : 22-7.

[22] Herzenberg JE, Radler C, Bor N : Ponseti versus traditional methods of casting for idiopathic clubfoot. J. Pediatr. Orthop. 2002; 22 (4) : 517-521.

[23] Pirani S, Outerbridge H, Moran M, Sawatsky B : A method of evaluating the virgin club foot with substantial interobserver reliability. Presented at the annual meeting of Pediatric Orthopaedic Society of North America, Miami, 1995.

[24] Ponseti IV : Congenital Clubfoot. Fundamentals of Treatment. New York Oxford University Press, 1996.
[25] Staheli L : Clubfoot : Ponseti Management. 2nd Ed. Global Help Publication, 2005.

[26] Leeveg SJ, Ponseti IV : Long term results of treatment of congenital clubfoot. J Bone Joint Surg (Am) 1980; 62 :23-31.

[27] Lehman WB, Mohaideen A, Madan S, Scher DM, Van Bosse HJ, Iannacone M, Bazzi JS, Feldman DS : A method for the early evaluation of the Ponseti (Lowa) technique for the treatment of idiopathic clubfoot. J. Pediatr. Orthop. B 2003; 12 (2) : 133-140.

[28] Scher DM, Feldman DS, van Bosse HJ, Sala DA, Lehman WB : Predicting the need for tenotomy in the Ponseti method for correction of clubfeet. J. Pediatr Orthop. 2004; 24 (4) : 349-52.

[29] Ponseti IV : Relapsing clubfoot : causes, prevention and treatment lowa. Orthop. J. 2002; 22 : 55-56. 